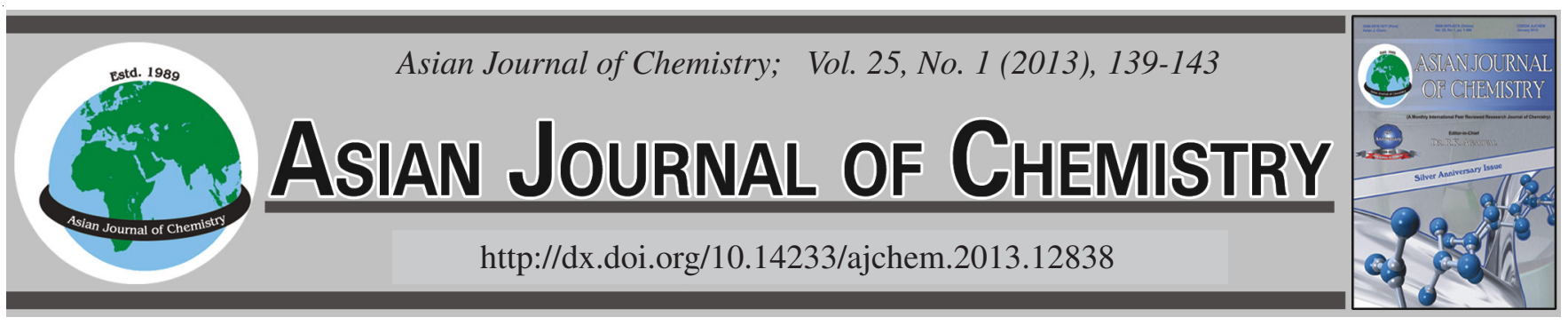

\title{
Synthesis and Characterization of Fluorinated Polyimide/Silica Nanocomposites with Low Water Absorption and Dielectric Constant
}

\author{
Guowen HE ${ }^{1,2}$, Hengfeng Li ${ }^{2, *}$, JiAngCong Chen ${ }^{2}$, Jun Chen ${ }^{2}$ and Jiebin Wen ${ }^{2}$
}

${ }^{1}$ College of Chemical and Environmental Engineering, Hunan City University, Yiyang 413000, P.R. China

${ }^{2}$ School of Materials Science and Engineering, Central South University, Changsha 410083, P.R. China

*Corresponding author: Fax: +86 731 88877873; Tel: +86 731 88877873; E-mail: zhongyipp@ 163.com

\begin{abstract}
A fluorine-containing polyimide(FPI) was synthesized by reacting 4,4'-(hexafluoroisopropylidene) diphthalic anhydride (6FDA) with 2,2'-bis-(trifluoromethyl)-4,4'-diaminobiphenyl (TFDB). A series of polyimide composite films with various contents of nanosilica were prepared by an in situ polymerization technique. The obtained composite materials were analyzed with FTIR and the results showed that the amino groups were completely imidized. The morphology of the composites was characterized with SEM and the results indicated that the nanosilica particles integral dispersed but micro-aggregated in the fluoro-contained polyimide matrix if the nanosilica content excessed $10 \mathrm{wt} \%$. The nanocomposite films were found to hold comparable thermal stability with the pure fluoro-contained polyimide film. The humidity absorption rate decreased with the increase of silica content. The dielectric constant of fluoro-contained polyimide/ nanosilica films decreased with increasing the frequency and exhibited an arch curve profile with its maximum value of less than 3 , indicating the excellent dielectric property.
\end{abstract}

Key Words: Polyimides, Nanosilica, Dielectric properties, Water absorption.

\section{INTRODUCTION}

Polyimides (PIs) exhibit a number of outstanding properties such as thermal stability, electrical behaviour, etc. ${ }^{1,2}$ and have found in broad applications in packaging materials, aerospace and so $\mathrm{on}^{3,4}$. All the polyimides are frequently used as interlayer dielectric insulators (ILD). To achieve maximum possible running speed in a limited dimensions, insulating materials with dielectric constant as small as possible are preferred. Polyimides with increasingly low dielectric constant and humidity absorption rate have being become the focus of several recent investigations ${ }^{5-8}$. As reported preparation of the matrix of fluorinated polyamide (FPI) and the incorporation of inorganic micro- or nano-fillers such as silica nanoparticles are a feasible way of improving these properties. For example, fluorination can impart the resulting fluorinated polyamides with the decreased dielectric constants because of the lower polarizability of fluorine $e^{9-11}$.

On the other hand, the polyimide/ $\mathrm{SiO}_{2}$ composites have been found to exhibit the good thermal properties ${ }^{12,13}$, low humidity absorption ${ }^{14}$, decreased dielectric constant ${ }^{15}$ and improved optical properties ${ }^{16}$. More importantly, the introduction of silica into polyimide films could increase the hydrophobicity, reducing the humidity absorption with a lower dielectric constant reached ${ }^{17}$.
This paper reports a study on the new fluorinated polyamide (6FDA-TFDB)/silica nanocomposite thin films obtained by reacting 4,4'-(hexafluoroisopropylidene) diphthalic anhydride (6FDA) with 2, 2'-bis-(trifluoromethyl)-4,4'-diaminobiphenyl (TFDB). Instead of using poly(amic acid) (FPAA) to prepare the silica composite materials, a soluble fluorinated polyamide (Scheme-I) was prepared from 6FDA and TFDB. Its molecular, the morphology, thermal, electrical and optical properties of the resulting fluorinated polyamide/silica nanocomposite thin films were analyzed with FTIR, TGA, SEM, UV-VIS and capacitance. In addition, the effects of the nanosilica content on the structure and properties of the prepared composite films are examined.

\section{EXPERIMENTAL}

Nanosilica produced via vapour method were purchased from Zhonggui High-Technology Co., Ltd. (Luoyang, China) with an particle size of $15-30 \mathrm{~nm}$ and a specific surface area of $150 \mathrm{~m}^{2} / \mathrm{g}$. 4, 4'-(hexafluoroisopropylidene)diphthalic anhydride and 2,2'-bis-(trifluoromethyl)- 4,4'diaminobiphenyl (Shanghai Chemical Reagent Co., China) were purified by vacuum sublimation. $N, N$-dimethylacetamide was distilled over powdered calcium hydride under reduced pressure and stored over $4 \AA$ molecular sieves prior to use. 
Preparation of fluorinated polyamide/silica nanocomposite films: The fluorinated polyamide was synthesized according to the literature ${ }^{18}$. The polymerization process of fluorinated polyamide/silica nanocomposite materials is illustrated in Scheme-I.
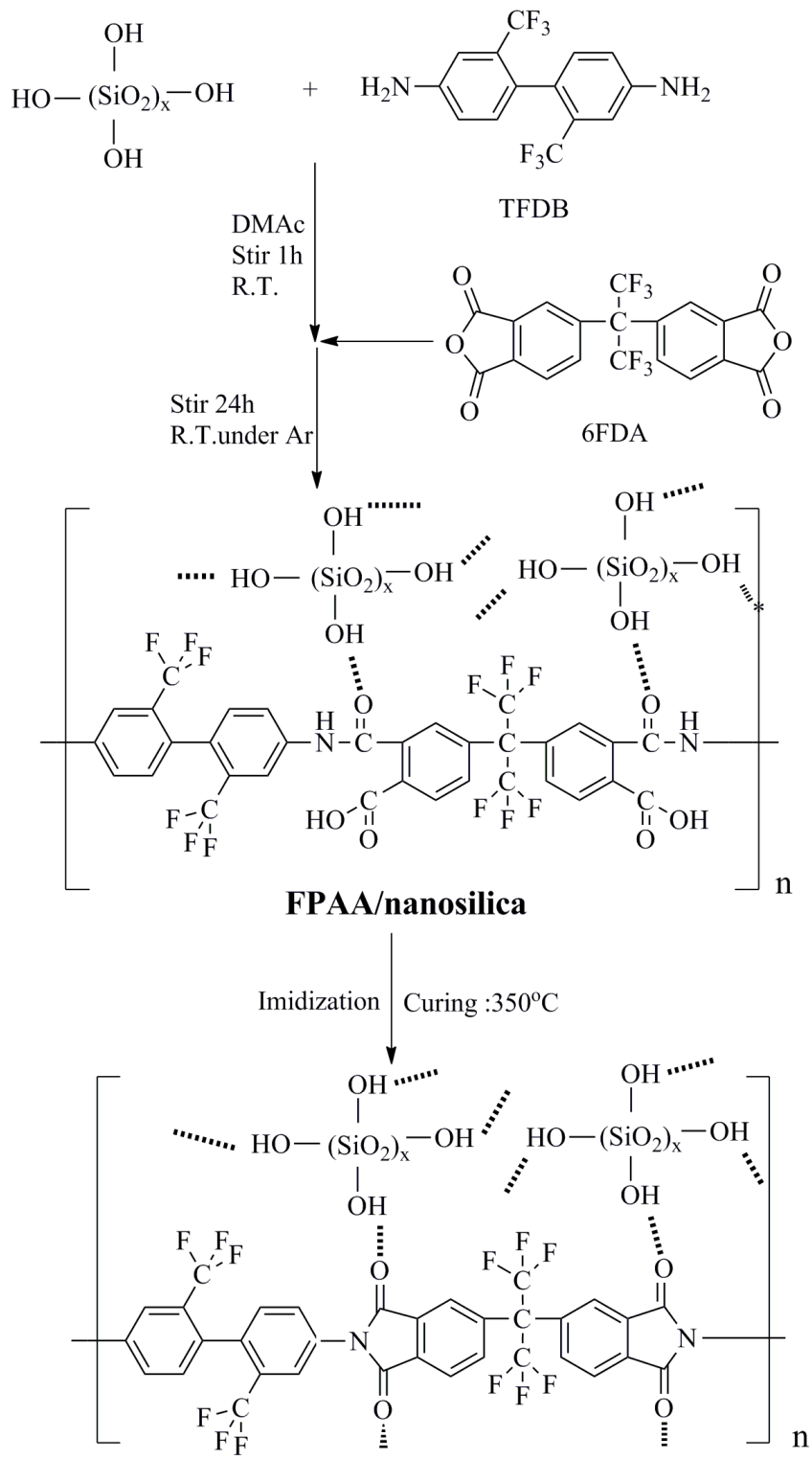

FPI/nanosilica

Scheme-I: Reaction scheme for fluorinated polyamide/silica nanocomposite materials (the"

To a $100 \mathrm{~mL}$ round-bottom flask $3.2 \mathrm{~g}(0.01 \mathrm{~mol})$ of TFDB and $20 \mathrm{~mL}$ dimethyl acetamide were added at room temperature with the slow stirring speed until a clear solution of diamine was obtained. To this solution, a calculated weight of nanosilica was added vigorous stirring for $1 \mathrm{~h}$ at room temperature. Followed by the stepwise addition of 6FDA (4.573 g, 0.0103 $\mathrm{mol}$ ) in 30 min under argon flow. A sticky and homogenous suspension fluorinated polyamic acid (FPAA)/nanosilica was obtained after stirring under an argon and at room temperature for $24 \mathrm{~h}$. The FPAA/nanosilica solution was casted on a clean glass substrate (cleaned with ultrasonic treatment, methanol and demonized water), rotated to form an even gel film and then was heated sequentially under vacuum at 50, 80, 120, $150,200,250,300$ and $350^{\circ} \mathrm{C}$ for $3,2,1,1,1,1,1$ and $1 \mathrm{~h}$ respectively. After that the composites films were immersed into deionized water for $2 \mathrm{~h}$, peeled off from the substrates and heated at $120^{\circ} \mathrm{C}$ for $2 \mathrm{~h}$ under nitrogen flow, then the fluorinated polyamide/silica nanocomposite films obtained.

Characterization: FTIR spectra were recorded on a Nicolet 6700 spectrometer with a wave number range from 4000 to $400 \mathrm{~cm}^{-1}$. The morphology of composite films and nanosilica were examined with a scanning electron microscopy (SEM, FEI SIRION 200). Ultraviolet-visible optical transmittances of the films were recorded on a UV-VIS spectrophotometer (Unocal UV-4802 s). Thermal-gravimetric analysis (TG) were performed with a NETZSCH TGA 200 F3 thermal analyzer at a heating rate of $10^{\circ} \mathrm{C} / \mathrm{min}$ under argon flow. The electrical capacitance was measured with a KEITHLEY 4200-SCS semiconductor characterization system at different frequency. The dielectric constant was calculated by using the following equation ${ }^{19}$ :

$$
\varepsilon=\frac{\mathrm{C} \cdot \mathrm{d}}{\varepsilon_{0} \cdot \mathrm{S}}
$$

where, $\mathrm{C}$ is the electrical capacitance, $\varepsilon$ is the dielectric constant, $\varepsilon_{0}$ is the permittivity of the free space $\left(8.85 \times 10^{-14} \mathrm{~F} / \mathrm{cm}\right)$, $\mathrm{d}$ and $\mathrm{S}$ are the film thickness and electrode area, respectively.

The water absorption values of the obtained films were determined at $30^{\circ} \mathrm{C}$. Before the measurement, the films were vacuum-dried for $24 \mathrm{~h}$ at $100{ }^{\circ} \mathrm{C}$, for then were weighed and immersed in deionized water for $24 \mathrm{~h}$. The wet films were wiped dry and quickly weighed. The humidity absorption of the films was calculated in weight per cent as follows ${ }^{20}$ :

Water absorption rate $=\left[\left(\mathrm{W}_{2}-\mathrm{W}_{1}\right) / \mathrm{W}_{1}\right] \times 100 \%$ where, $\mathrm{W}_{2}$ is the weight of thin film after absorption water and $\mathrm{W}_{1}$ is the weight of dry film.

\section{RESULTS AND DISCUSSION}

Structure of the fluorinated polyamide/silica nanocomposites: FTIR spectra of the prepared fluorinated polyamide/silica nanocomposite films containing $3 \mathrm{wt} \%$ of silica are shown in Fig. 1. Where the corresponding characteristic absorption peaks of the fluorinated polyamide matrix and the $\mathrm{Si}-\mathrm{O}-\mathrm{Si}$ stretching bands $\left(1120 \mathrm{~cm}^{-1}\right)$ of the curve of fluorinated polyamide $/ \mathrm{SiO}_{2}(3 \mathrm{wt} \%)$ are highlighted. The imide groups or functionalities of fluorinated polyamide and FPAA are further supported. The bands observed around $1786 \mathrm{~cm}^{-1}(\mathrm{C}=\mathrm{O}$, symmetrical stretching), $1727 \mathrm{~cm}^{-1}(\mathrm{C}=\mathrm{O}$, asymmetrical stretching), $719 \mathrm{~cm}^{-1}$ (C=O bending) $1370 \mathrm{~cm}^{-1}$ (C-N stretching), C-NH (1540 $\mathrm{cm}^{-1}$, symmetrical stretching; $1332 \mathrm{~cm}^{-1}$ and asymmetrical stretching) and $\mathrm{COOH}\left(2940 \mathrm{~cm}^{-1}\right)$. In contrast, the characteristic band of polyamic acid around $1680 \mathrm{~cm}^{-1}$ is not found on the curves of fluorinated polyamide and its composite. In addition, the IR absorption of the $\mathrm{O}-\mathrm{H}$ group and $\mathrm{N}-\mathrm{H}$ group of the FPAA have disappeared, indicating that the imidization reaction was completed via the heating process and the fluorinated polyamide synthesized. There are no free amine group. This conclusion can be hardly obtained from 


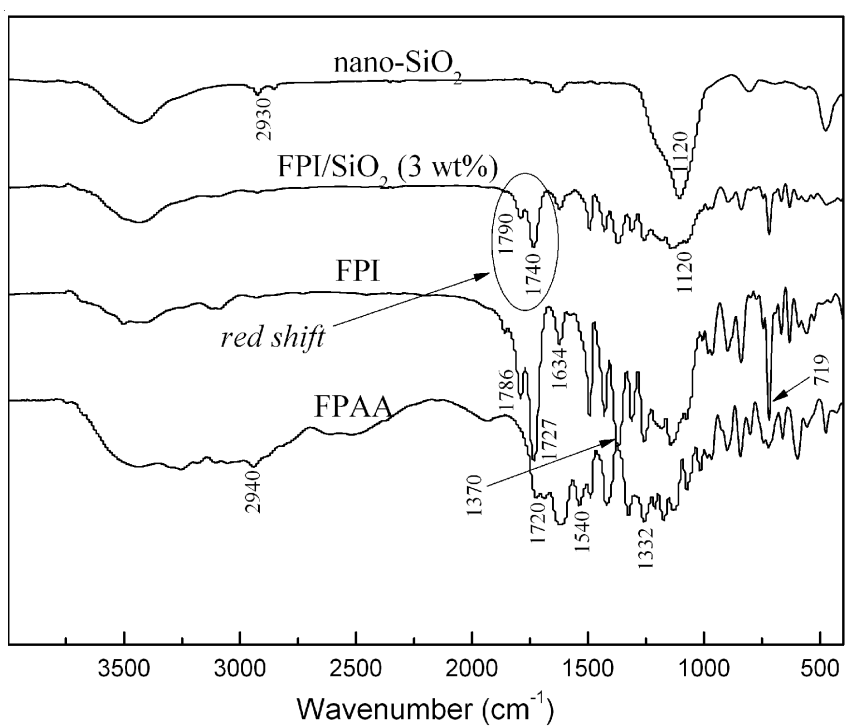

Fig. 1. FTIR spectra of nanosilica, FPAA, fluorinated polyamide and fluorinated polyamide composite containing $3 \mathrm{wt} \%$ nanosilica

the absorption of $\mathrm{N}-\mathrm{H}$ and $\mathrm{OH}$, as shown $3500 \mathrm{~cm}^{-1}$ detected in the final spectra of the composite films, which indicates the successful incorporation of the nanosilica to the resulting composites films. Furthermore, the addition of nanosilica caused the absorption band of $\mathrm{C}=\mathrm{O}$ slightly red shift in the fluorinated polyamide/silica nanocomposites, which can be attributed to the hydrogen-bonding between the $\mathrm{O}-\mathrm{H}$ of nanosilica and the oxygen atoms in fluorinated polyamide.

The effect of the organic/inorganic interface compatibility on the mechanical properties can be estimated by observing the fracture surface of the specimen by using a SEM. Fig. 2(a) shows the typical SEM images of the nanosilica particles. The $\mathrm{SiO}_{2}$ nanoparticles are gathered in a loose state with the average diameter of about $15 \mathrm{~nm}$. The cross-sectional fractures of the nanocomposites with a nanosilica loading of $3 \mathrm{wt} \%$ as showed in Fig. 2(b). The $\mathrm{SiO}_{2}$ nanoparticles can be integral dispersed at low content in the fluorinated polyamide matrix.

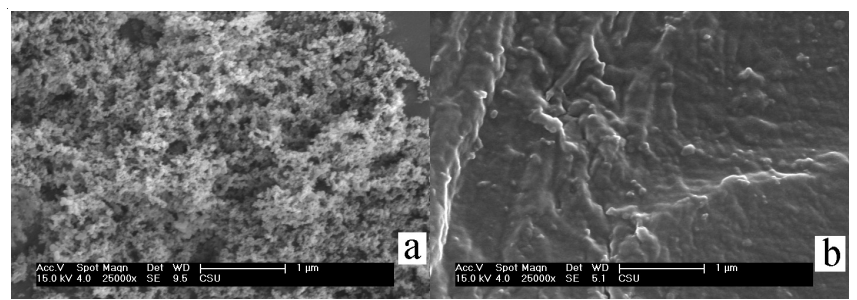

Fig. 2. SEM images of the nanosilica particles (a) and the broken section of fluorinated polyamide nanocomposite film containing $3 \mathrm{wt} \%$ nanosilica (b)

Fig. 3 is the schematic diagram of the silica nanoparticles, showing structural charactertics and linkages among $\mathrm{Si}, \mathrm{O}$ and $\mathrm{H}$ atoms. A large number of the hydroxy groups distributed in the core and at surface of the silica particles, which could account for the $\mathrm{H}$-bonding between the $\mathrm{SiO}_{2}$ nanoparticles and the fluorinated polyamide matrix, further improving the dispersion of $\mathrm{SiO}_{2}$. This conclusion is supported analysis of nanosilica FTIR spectra.

Table-1 presents the thermal properties and transmittance of fluorinated polyamide nanocomposite thin films with different

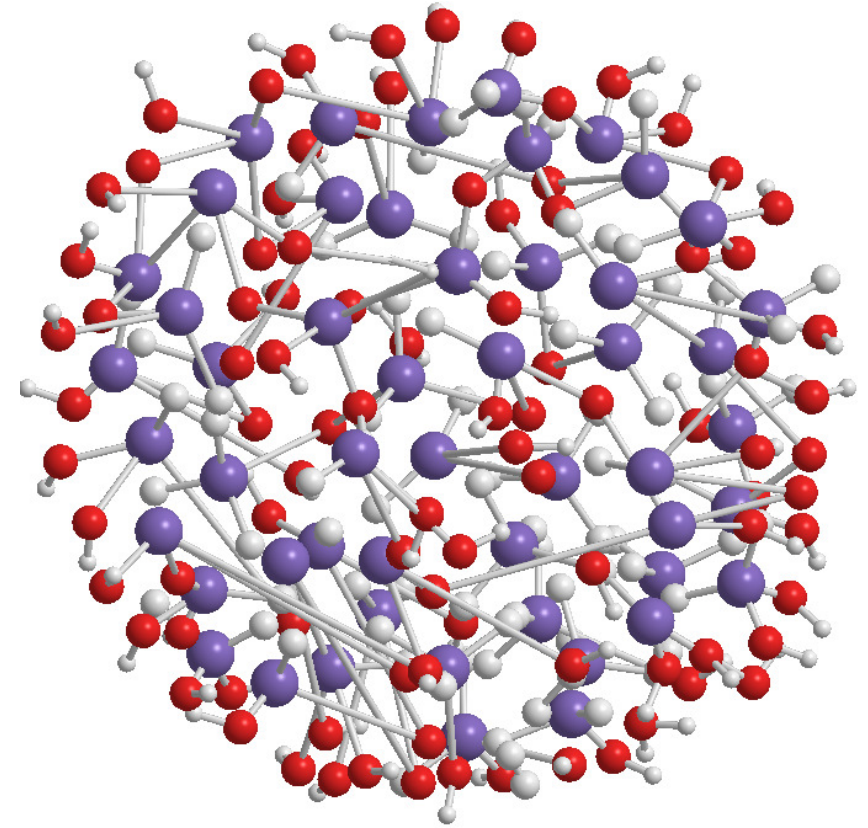

Fig. 3. Ideal structure of the $\mathrm{SiO}_{2}$ nanoparticles

contents of silica. The pure fluorinated polyamide shows the excellent thermal stability with the temperature for $5 \%$ weight loss of $531^{\circ} \mathrm{C}$. The thermal stability of the fluorinated polyamide nanocomposites with different nanosilica contents were better than that of the pure fluorinated polyamide, their Tg and temperatures for $5 \%$ weight loss increased with adding of nanosilica and were higher than $314{ }^{\circ} \mathrm{C}$ and $530{ }^{\circ} \mathrm{C}$, respectively. This performance is acceptable for polyimide-based materials in most practical applications with the thermally resistant requirement.

As shown in Table-1, the transmittance of the prepared composite thin films excessed $88 \%$ at $500 \mathrm{~nm}$ and $600 \mathrm{~nm}$ and showed a trend of enlarging with adding nanosilica to fluorinated polyamide, had a low cutoff wavelength with indicating excellent optical transparency. It can be said that the composite thin films have a high homogeneity because of their better transparency compared to that of pure fluorinated polyamide without nanosilica ${ }^{3}$.

\begin{tabular}{ccccc}
\multicolumn{5}{c}{ TABLE-1 } \\
$\begin{array}{c}\text { PHYSICAL PROPERTIES OF FLUORINE CONTAINED } \\
\text { POLYIMIDE COMPOSITE THIN FILMS WITH }\end{array}$ \\
\multicolumn{4}{c}{ DIFFERENT CONTENTS OF NANOSILICA } \\
\hline $\begin{array}{c}\text { Silica content } \\
(\text { wt \% })\end{array}$ & \multicolumn{2}{c}{ Transmittance } & Tg & Temperature $\left({ }^{\circ} \mathrm{C}\right)$ \\
\cline { 2 - 3 }$(\%)$ & ${ }^{\mathrm{b}}(\%)$ & $\left({ }^{\circ} \mathrm{C}\right)$ & for $5 \%$ weight loss \\
\hline 0.0 & 88.3 & 88.4 & 314 & 531 \\
0.5 & 88.5 & 88.7 & 316 & 533 \\
1.0 & 88.4 & 89.0 & 318 & 535 \\
3.0 & 89.2 & 89.4 & 321 & 536 \\
7.5 & 90.2 & 90.5 & 326 & 540 \\
10.0 & 90.8 & 90.8 & 330 & 545 \\
15.0 & 90.7 & 90.9 & 332 & 549 \\
20.0 & 91.2 & 91.6 & 335 & 555 \\
25.0 & 91.3 & 91.5 & 337 & 561 \\
\hline${ }^{\mathrm{a} O p t i c a l ~ t r a n s m i t t a n c e ~ a t ~} 500 \mathrm{~nm} ;{ }^{\mathrm{b}}$ Optical transmittance at $600 \mathrm{~nm}$
\end{tabular}

Water absorption property of the fluorinated polyamide/silica nanocomposite films: A necessary consideration 
for application of polyimides in microelectronics is the humidity absorption and hydrothermal resistance. Fig. 4 demonstrates water absorption as a function for the fluorinated polyamide nanocomposite films with various nanosilica particle contents. Clearly, the water absorptions of the fluorinated polyamide/nanosilica composite films are all smaller than that of the pure fluorinated polyamide film and decreased with the increased nanosilica content, indicating that it is easier for water molecules to diffuse into the fluorinated polyamide matrix without the nanosilica filler. The diffusion of water molecules becomes more difficult in the fluorinated polyamide composite films. That was attributed to the strong hydrophobicity of the $\mathrm{SiO}_{2}$ nanoparticles though they contain hydrophilic groups (-OH). In addition, for fluorinated polyamide, it's fluorine content with $31.3 \%^{18}$, can be synthesized by reacting monomers 6FDA with TFDB, both of which bear two trifluoromethyl groups, thus exhibiting favourable hydrophobicity $^{21}$.

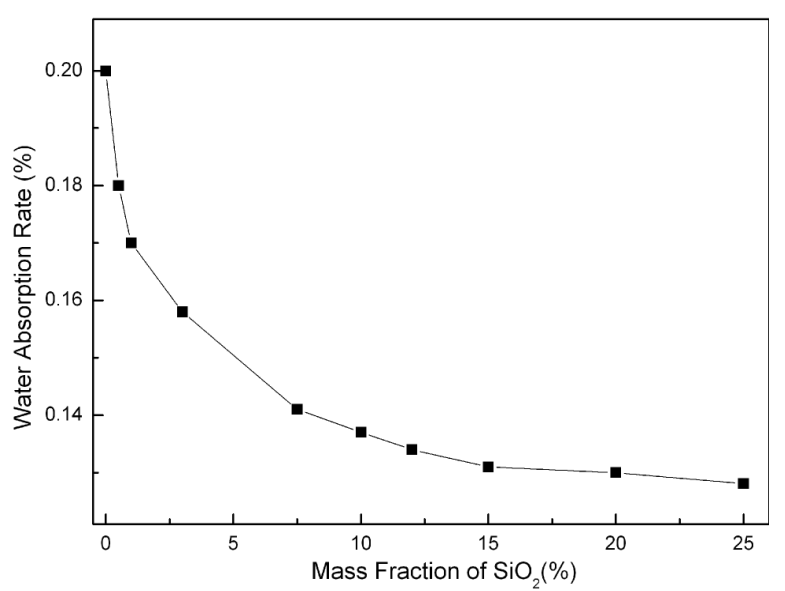

Fig. 4. Water absorption of the films with different $\mathrm{SiO}_{2}$ content (the average thickness of films was $8.5 \times 10^{-5} \mathrm{~m}$ )

Dielectric characteristics of the fluorinated polyamide/ silica canocomposites: The dielectric constants of the prepared composite thin films at three different frequencies were listed in the Table-2. As results, the dielectric constant of pure fluorinated polyamide has the value between 2.78 and 2.81 depending on the applied frequencies. For the composites, their dielectric constants increase firstly along with the nanosilica load, reach the maximum value at the $10 \mathrm{wt} \%$ of nanosilica and then decrease with the nanosilica load.

\begin{tabular}{cccc}
\multicolumn{4}{c}{ TABLE-2 } \\
\multicolumn{4}{c}{ DIELECTRIC CONSTANT OF THE NANOSILICA/FPI } \\
COMPOSITES \\
\hline \multirow{2}{*}{ Sample } & \multicolumn{2}{c}{ Dielectric constant at different frequency } \\
\cline { 2 - 4 } & $\mathrm{f}=50 \mathrm{KHz}$ & $\mathrm{f}=100 \mathrm{KHz}$ & $\mathrm{f}=500 \mathrm{KHz}$ \\
\hline $\mathrm{FPI}$ & 2.812 & 2.800 & 2.780 \\
$0.5 \mathrm{wt} \% \mathrm{SiO}_{2} / \mathrm{FPI}$ & 2.820 & 2.813 & 2.803 \\
$1.0 \mathrm{wt} \% \mathrm{SiO}_{2} /$ FPI & 2.837 & 2.826 & 2.816 \\
$3.0 \mathrm{wt} \% \mathrm{SiO}_{2} / \mathrm{FPI}$ & 2.863 & 2.858 & 2.838 \\
$7.5 \mathrm{wt} \% \mathrm{SiO}_{2} /$ FPI & 2.980 & 2.948 & 2.920 \\
$10 \mathrm{wt} \% \mathrm{SiO}_{2} / \mathrm{FPI}$ & 2.994 & 2.960 & 2.948 \\
$15 \mathrm{wt} \% \mathrm{SiO}_{2} / \mathrm{FPI}$ & 2.950 & 2.890 & 2.866 \\
$20 \mathrm{wt} \% \mathrm{SiO}_{2} / \mathrm{FPI}$ & 2.937 & 2.865 & 2.832 \\
$25 \mathrm{wt} \% \mathrm{SiO}_{2} / \mathrm{FPI}$ & 2.790 & 2.780 & 2.760 \\
\hline
\end{tabular}

The increase of the dielectric constant is mainly attributed to the relatively high dielectric constant of nanosilica particles (about 3.8-3.9) ${ }^{22}$ incorporated into fluorinated polyamide matrix and the strong interactive interface between the inorganic nanosilica and the organic fluorinated polyamide matrix. This effect was also corresponded to the sum property principle of polymer composites, i.e., $\varepsilon_{\min }<\varepsilon<\varepsilon_{\max }{ }^{19}$. Moreover, the flaws introduced by the incorporating of nanosilica phase, such as the electrons, cavities, vacancies, etc., changed the distribution of charge in composite films and under electric field, the charges migrated to the positive and negative electrode, respectively, leading the charges accumulating in the interfacial flaws. The orientation polarization of interfacial charges, which was also called interfacial charge polarization, took place as a consequence of charge migration, bringing about the dielectric coefficient of hybrid films increasing. It also can be remarkably seen that the growth trend of $\varepsilon$ towards frequency was obedient to the change trends at a low frequency forecasted by Debye relaxation theory $(\omega \pi<<1$ or $2 \pi f<<1)$. The $\varepsilon$ decreased with the increasing of $\mathrm{SiO}_{2}$, presumably due to the movement of chain segments and the interfacial polarization were hindered as the large and compact $\mathrm{SiO}_{2}$ network formed with increased $\mathrm{SiO}_{2}$ content.

Kramarenko et al. ${ }^{22}$ pointed out that the relationship of composition dependence of $\varepsilon$ of the $\mathrm{SiO}_{2}$ suggested a probability of a morphology change, presumably, a sort of percolation transition from small-size, individual clusters into large-size, infinite clusters and fluorinated polyamide derived nanoparticles may have a reasonably good potential as low dielectric constant materials ${ }^{6}$.

\section{Conclusion}

A series of fluorinated polyamide/silica nanocomposite thin films were successfully prepared via in situ polymerization of TFDB and 6FDA in the presence of nanosilica particles. The nanocomposite films hold the preferable thermal stability as same as the pure fluorinated polyamide. Their water absorption decreased with increasing of the silica content. The dielectric constant of fluorinated polyamide/nanosilica films decreased with the increased frequency. As the silica contents increased, the dielectric constant of composite films slightly increased gradually up to $10 \mathrm{wt} \%$ silica; after decreased. The films possessed the low dielectric constant for all compositions. In summary, the fluorinated polyamide/silica is a kind of nanocomposites material with to be specific properties, showing a great potential for practical applications in high performance microelectronic devices and electron packaging.

\section{ACKNOWLEDGEMENTS}

The authors acknowledged the Natural Science Foundation of Hunan Province of China (NSF, Grant No. 10JJ5057) for financial support.

\section{REFERENCES}

1. S. Banerjee, M.K. Madhra, A.K. Salunke and G. Maier, J. Polym. Sci., Part A: Polym. Chem., 40, 1016 (2002).

2. Y. Watanabe, Y. Shibasaki, S. Ando and M. Ueda, Polymer, 46, 5903 (2005).

3. T. Suzuki, Y. Yamada and K. Itahashi, J. Appl. Polym. Sci., 109, 813 (2008). 
4. M. Rubal, C.W. Wilkins, P.E. Cassidy, C. Lansford and Y. Yamada, Polym. Adv. Technol., 19, 1033 (2008).

5. T. Liang, Y. Makita and S. Kimurs, Polymer, 42, 4867 (2001).

6. L.Y. Jiang, C.M. Leu and K.H. Wei, Adv. Mater, 14, 426 (2002).

7. C.-P. Yang, S.-H. Hsiao and K.-H. Chen, Polymer, 43, 5095 (2002).

8. M.K. Madhra, A.K. Salunke, S. Banerjee and S. Prabha, Macromol. Chem. Phys., 203, 1238 (2002).

9. S.-J. Park, K.-S. Cho and S.-H. Kim, J. Colloid. Interf. Sci., 272, 384 (2004).

10. S. Srisuwan, S. Thongyai and P. Praserthdam, J. Appl. Polym. Sci., 117, 2422 (2010).

11. K.-Y. Chen and J.-F. Kuo, Macromol. Chem. Phys., 201, 2676 (2000).

12. P.V. Komarov, Y.-T. Chiu, S.-M. Chen and P. Reineker, Macromol. Theory Simul., 19, 64 (2010).

13. H. Wang, W. Zhong, P. Xu and Q. Du, Macromol. Mater. Eng., 289 , 793 (2004).
14. J.C. Tang, G.L. Lin, H.C. Yang, G.J. Jiang and Y.W. Chen-Yang, J. Appl. Polym. Sci., 104, 4096 (2007).

15. W.-D. Liu, B.-K. Zhu, J. Zhang and Y.-Y. Xu, Polym. Adv. Technol., 18, $522(2007)$

16. Y.-Y. Yu, W.-C. Chien, C.-L. Lai, Mater. Chem. Phys., 113, 567 (2009).

17. E. Hamciuc, C. Hamciuc and M. Olariu, Polym. Eng. Sci., 50, 520 (2010).

18. T. Matsuura, Y. Hasuda, S. Nishi and N. Yamada, Macromol., 24, 5001 (1991).

19. C.-W. Nan, Prog. Mater. Sci., 37, 1 (1993).

20. B.R. Einsla, S.K. Yu, M.A. Hickner, Y.-T. Hong, M.L. Hill, B.S. Pivovar and J.E. McGrath, J. Membr. Sci., 255,141 (2005).

21. K. Xie, J.G. Liu, H.W. Zhou, S.Y. Zhang, M.H. He, M.H. He and S.Y. Yang, Polymer, 42, 7267 (2001).

22. V. Yu. Kramarenko, T.A. Shantalil, I.L. Karpova, K.S. Dragan, E.G. Privalko, V.P. Privalko, D. Fragiadakis and P. Pissis, Polym. Adv. Technol., 15, 144 (2004). 